\section{Integrating Spatial Technology into Feldtrips within Elementary Geography Education}

GI_Forum 2018, Issue 2

Page: 214 - 226

Full Paper

Corresponding Author:

kuohung@mail.ncyu.edu.tw

DOI: 10.1553/giscience2018_02_s214

\author{
Kuo-Hung Huang \\ National Chiayi University, Ta iwan
}

\begin{abstract}
Thanks to the rapid development of spatial technology, people can now easily access global geographic information. Geography education in schools faces the need to integrate spatial technology with fieldwork. The purpose of this research is to combine geospatial information and fieldtrips to promote elementary-school students' leaming in the national geography curric ulum. During a GIS camp, students were taught to use Google Earth, Google Maps and desktop GIS. They were then guided to do fieldwork and mapping of their local area so that they would know how to geotag interesting local spots by themselves.
\end{abstract}

Observation and questionnaires were used to understand the students' leaming progress. Sketch-map analysis was adopted to evaluate the development of their map skills and geography capability. The results indicated that students' map skills and geography knowledge increased. Students actively participated in the activities and showed a positive attitude towards leaming using Google Maps and Google Earth rather than GIS software.

\title{
Keywords:
}

spatial tec hnology, fieldtrip, geography education, GIS, homeland education

\section{Introduction}

Ideal geography instruction emphasizes the thinking process and outcomes (Shin, 2006). Instead of spending a long time memorizing decontextualized facts, students should focus on learning about why things are where they are. To positively enhance students' learning, fieldtrips provide sensorial experiences in geographical issues and processes. Field experience within the local area motivates students to actively participate in discovering relevant places and making sense of them in the context of a particular topic (Fuller, 2006; Gaillard \& McSherry, 2014). Prior studies indicate that fieldtrips combining classroom and field activities help students to engage in a process of inquiry (Huang, 2011b; Remmen \& Froyland, 2013). Moreover, using space as a framework to understand local affairs helps students to develop observational skills and to synthesize complex information about the world around them. 
With the ability to provide large amounts of visual information efficiently, mapping tools such as GIS or Google Earth offer new ways to present spatial information and deliver an engaging learning experience. The rapid development of GIS software and web-based map services has led to a significant increase in the numbers of schools and teachers adopting GIS in geography education. Many organizations and individuals promote the use of GIS in geography education for years K through to 12 (Kawabata, Thapa, Oguchi \& Tsou, 2010; Kerski, Demirci \& Milson, 2013; Nielsen, Oberle \& Sugumaran, 2011; Perkins, Hazelton, Erickson \& Allan, 2010; Rickles \& Ellul, 2017).

Numerous studies focusing on education at secondary and college levels have yielded promising results, with GIS leading to improvements in motivation and geography learning. However, recent studies involving GIS and elementary students are limited (Huang, 2011a; Jadallah et al., 2017). In order to reduce this gap in the knowledge base, this study investigated how spatial technologies used in fieldtrips influenced elementary students' map skills and geographic knowledge.

As a tool for the presentation of location-based subject matter, GIS provides students with hands-on opportunities in using geographic data to answer complex questions. For elementary students, how to select and integrate appropriate spatial technologies with fieldbased learning activities is a critical component of the geography curriculum. Thus, this study aimed to understand the interacting effects of combining spatial technologies with fieldtrips and their influence on elementary students' geography learning.

\section{Research method and design}

\section{Research Design}

In order to develop students' geography capabilities, including their geographical knowledge and map skills, a project-based learning approach was adopted for instruction. Designed to interweave spatial technology practice with its application in fieldtrips to make learning meaningful and effective, the study was conducted during a two-day weekend camp on spatial technology. The camp was cost-free and held in an elementary school. The schedule of learning activities is shown in Table 1.

During the first day, students were introduced to Google Maps and Google Earth before a fieldtrip around the neighbouring area during which they geotagged photographs. After the fieldtrip, the photographs were shown, leading to a discussion of the unique features of the local community area. Two map-sketching activities on the local area were conducted, one at the beginning of Day 1 and one at the start of Day 2, in order to assess students' progress in geography learning influenced by the activities of Day 1.

On Day 2, the students were introduced to GIS software, after which they had another fieldtrip to take geotagged photographs. Afterwards, students used the GIS software and data from the fieldtrip to produce a thematic map. Finally, students shared what they had designed and their attitudes towards spatial technology and homeland geography. 
This study adopted qualitative and quantitative methods to investigate students' changes in spatial abilities and geography knowledge. For quantitative research, students' sketch maps were analysed. Qualitative data, including observation of the participants, interviews, and the maps produced, were analysed to understand the students' learning trajectory.

Table 1: Schedule of Lea ming Activities

\begin{tabular}{lll}
\hline \multicolumn{1}{c}{ Activities } & Place & Research Data Collection \\
\hline Day 1 & & \\
Registration & Classroom & Initial sketch map \\
Introduction to Google Earth & Computer Lab & \\
Exploratory fieldtrip planning & Computer Lab & Observation of participants \\
GPS and Camera Operation & Outdoors & \\
Exploratory fieldtrip & Outdoors & Observation of participants \\
Presentations and discussion & Computer Lab & Observation of participants \\
Concluding session & Classroom & \\
Day 2 & & \\
Registration & Classroom & Follow-up sketch map \\
Introduction to Quantum GIS & Computer Lab & \\
Sightseeing fieldtrip planning & Computer Lab & Observation of participants \\
Sightseeing fieldtrip & Outdoors & Observation of participants \\
Interactive map production & Computer Lab & \\
Presentations & Computer Lab & Observation of participants \\
Concluding session & Classroom & Interview \\
\hline
\end{tabular}

\section{Research participants}

An elementary school in a remote area of southern Taiwan was selected as the location for the research. The indoor activities took place in the computer lab, which was equipped with 20 computers. Recommended by the school teachers, 7 male and 9 female students took part in the study. The students were fifth and sixth graders (11 and 12 years old), who all had basic computer skills. As Table 2 indicates, half of the students were experienced in using Google Maps. Most had heard of spatial technologies like GPS, GIS or Google Earth but had no hands-on experience. All students attended the homeland course, on local geography and history, as a compulsory part of the social studies curriculum, but only one student had ever been on a fieldtrip in the local area.

The research team consisted of a professor and eight university students. Three Masters students majoring in educational technology were responsible for presentations during 
lessons and for the collection of research data. Five undergraduate students served as a teaching assistants to help participants use spatial technologies to produce their maps. In addition, the college students acted as participating observers and shared their reflections on curriculum and learning activities during the camp.

Table 2: Students' prior experiences in homeland education and spatial technologies

\begin{tabular}{lcccc}
\hline \multicolumn{1}{c}{ Questions } & N & Yes & No & No reply \\
\hline Attended any computer camp & 10 & 1 & 9 & 0 \\
Attended any homeland course & 10 & 10 & 0 & 0 \\
Fieldtrips in local community & 10 & 1 & 8 & 1 \\
Heard of GIS & 10 & 1 & 9 & 0 \\
Experience of using GIS software & 10 & 0 & 10 & 0 \\
Heard of GPS & 10 & 7 & 3 & 0 \\
Experience of using GPS & 10 & 1 & 9 & 0 \\
Heard of Google Earth & 10 & 4 & 6 & 0 \\
Experience of using Google Earth & 10 & 2 & 8 & 0 \\
Heard of Google Maps & 10 & 6 & 4 & 0 \\
Experience of using Google Maps & 10 & 5 & 5 & 0 \\
\hline
\end{tabular}

\section{Instruments}

Two different questionnaires were sent to students before and after the camp respectively. The first was designed to collect information regarding their experiences in spatial technology and geography education. The second aimed to collect student feedback on the camp's activities. Students were asked to rate their feelings towards each lesson on a 5-point Likert scale - for example, if they agreed that it was difficult to follow a specific lesson.

To understand how students develop detailed mental maps of the world, free-hand sketch maps, rather than a test on geographic information, are effective (Chiodo, 1997; Linn, 1997; Nieścioruk, 2016). A sketch map revealing a student's internal representation can be analysed to examine his/her understanding of the world. Furthermore, sketch maps can be scored and compared for empirical studies. For example, Chiodo used this method to assess learning achievement in geography, comparing lessons that had students construct and work with maps and lessons which simply required filling in information. Chiodo's scoring method for analysing sketch maps, revised and adopted in this study, evaluates students' sketch maps and rates them with a high, middle or low score according to the contents in seven categories: view, accuracy, roads, buildings, region boundary, colour and map keys. The rubric for scoring maps is shown as Table 3. The students' sketch map scores can be used as evidence for learning by comparing the pre-test map and the post-test map for each category. 


\section{Data collection and analysis}

At the beginning of Days 1 and 2, students were asked to hand-sketch a map of the neighbourhood. The first map was termed the "pre-test map" and the second one "the posttest map". The scores of the two were compared to reveal the influence of the first day's activities. T-test was used to check whether significant differences existed between pre-test and post-test scores.

In addition to the sketch-map analysis, observation of participating students' behaviour during classroom and fieldtrip activities provided authentic information. Questionnaires and individual interviews were also conducted to understand the students' attitudes towards the camp.

Table 3: Rubric for scoring map skills and geography content

\begin{tabular}{|l|l|l|l|}
\hline \multirow{2}{*}{ Item } & \multicolumn{3}{|c|}{ Score } \\
\cline { 2 - 4 } & \multicolumn{1}{|c|}{ Low (1) } & \multicolumn{1}{c|}{ Middle (2) } & \multicolumn{1}{c|}{ High (3) } \\
\hline View & Ground view & Partially applied aerial view & Aerial view \\
\hline Accuracy & Not accurate & $\begin{array}{l}1-2 \text { element(s) is/are } \\
\text { accurate }\end{array}$ & $\begin{array}{l}\text { 3 or more elements are } \\
\text { accurate }\end{array}$ \\
\hline Roads & No roads & $1-2$ roads & 3 or more roads \\
\hline Buildings & No buildings & $1-2$ buildings & 3 or more buildings \\
\hline $\begin{array}{l}\text { Region } \\
\text { boundary }\end{array}$ & $\begin{array}{l}\text { No distinct area } \\
\text { boundary }\end{array}$ & $\begin{array}{l}\text { Partially indicated distinct } \\
\text { area boundary on the map }\end{array}$ & $\begin{array}{l}\text { Indicated distinct areas on } \\
\text { the entire map }\end{array}$ \\
\hline Colour & $\begin{array}{l}\text { No colour or colour } \\
\text { not meaningful }\end{array}$ & $\begin{array}{l}\text { Partially used colour to } \\
\text { represent elements }\end{array}$ & $\begin{array}{l}\text { Used colour to represent } \\
\text { elements on the entire } \\
\text { map }\end{array}$ \\
\hline Map keys & No map keys & Map key with 1-2 elements & $\begin{array}{l}\text { Map key with 3 or more } \\
\text { elements }\end{array}$ \\
\hline
\end{tabular}

\section{Learning trajectory}

In addition to fieldtrips, four major spatial technologies were adopted in the learning activities, namely Google Maps and Google Earth, GPS and geotagging, as well as GIS software. Students first learned how to use the software and operate devices such as a GPS and a camera. They then used these technologies to plan, record and produce artefacts during fieldtrips.

\section{Spatial Technologies}

\section{Google Maps and Google Earth}

On Day 1, students learned to use Google Maps and Google Earth. They were asked to mark their homes and the routes to school on a satellite image before sharing their experiences of visiting various places in the local area. Finally, they cooperated in groups to plan routes for exploratory fieldtrips before producing the routes on Google Earth or 
Google Maps. They were encouraged to explore the area and record local places on the online map. Through the user-friendly Google Earth interface, students were familiarizing themselves with map reading and local geography.

\section{Geotagging}

Being easy to do and low-cost, geotagging has the potential to raise spatial awareness, enable basic mobile mapping, and provide basic GIS skills, as well as enhance the quantity of data collected. In this camp, geotagging of photographs was conducted because of its potential to complement reflective field diaries and to encourage further post-fieldwork student reflection and understanding of a landscape (Welsh, France, Whalley \& Park, 2012).

Before the fieldtrips, students learned to use the camera and GPS system as well as to synchronize the time of the two devices. After the fieldtrips, the photographs and navigation tracks were imported into Google Earth. As seen in Figure 1, navigation tracks and camera markers were overlayed on the satellite image.

\section{GIS Software}

In the morning of Day 2, students first learned how to use GIS software. Because it is free and easy to use, Quantum GIS was selected for producing thematic maps. After the production of the thematic maps, students were asked to design a sightseeing tour based on the local area. They discussed some interesting spots found in the fieldtrips on the previous day. In the end, students designed 3 tours, namely of cultural and religious sites, agricultural and aquaculture sites, as well as a large river.

Being confused by the GIS functions such as map layers and orientation, students encountered difficulties using the software. They needed considerable help from the GIS experts to produce a thematic map. The inappropriateness of using GIS software in the elementary curriculum was obvious based on students' feedback and on observing them using it.

\section{Fieldtrips}

\section{Exploratory fieldtrip}

In the afternoon of Day1, students conducted exploratory fieldtrips. Before the trips, students had been taught how to use the equipment, including GPS trackers, PDAs and cameras. During the fieldtrips, they walked along the planned itineraries and took pictures of interesting spots. Afterwards, their pictures were linked to Google Earth and shared with the other students. To refresh their memories, students also shared their feelings or personal experiences regarding particular spots on the fieldtrips.

\section{Designed fieldtrips}

In the designed fieldtrips, students, as three groups, navigated and recorded scenery on the route they had previously planned. The first route they designed was a culture and religion trail which visited temples, graves and gandangs (stone tablets or tiny houses erected to ward off evil spirits) (Figure 1). The second route was an agriculture and aquaculture itinerary visiting areas farming fish, crocodiles and turtles (Figure 2). The students' third route was along the big river, the Tsengwen (Figure 3). 


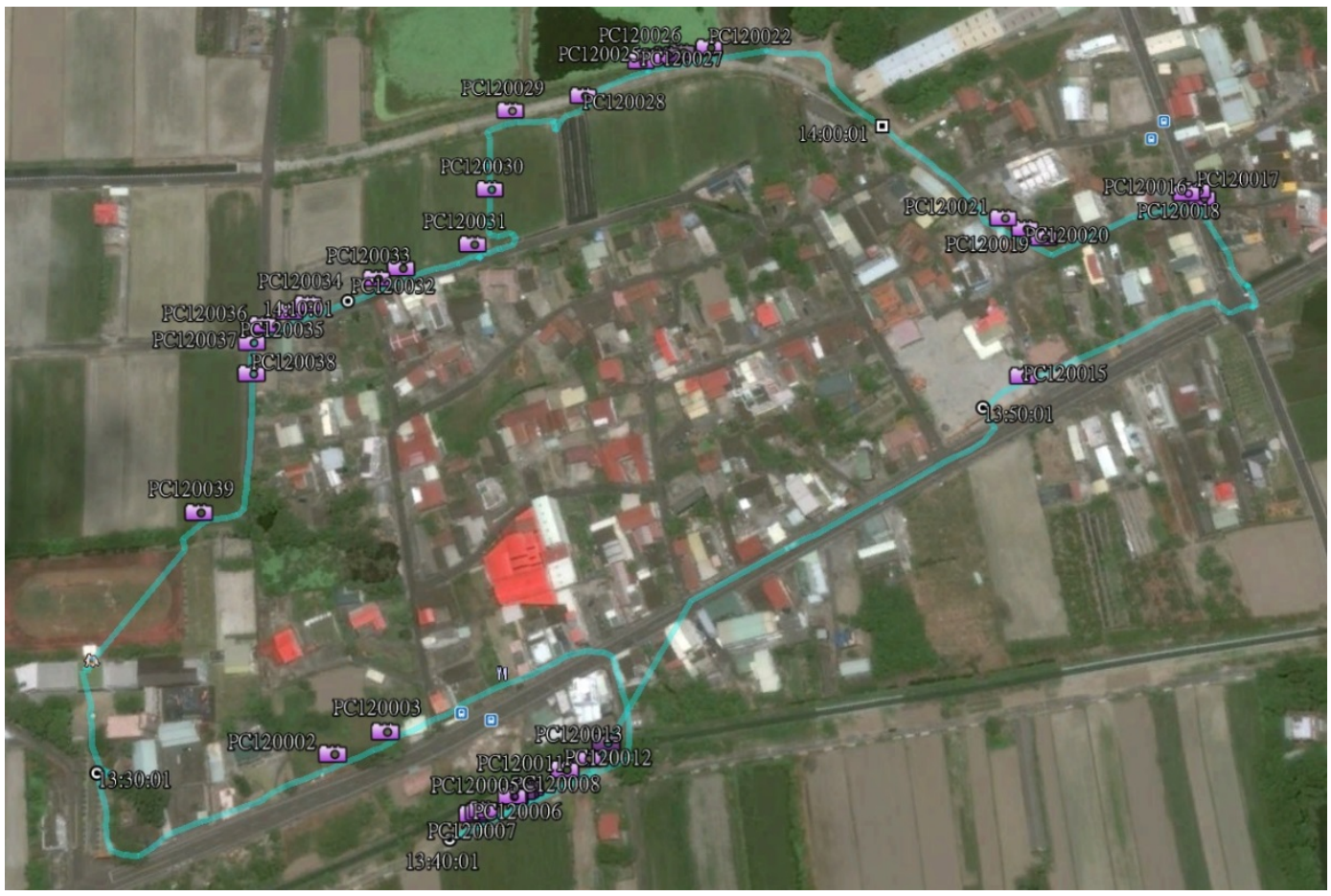

Figure 1: Itinera ry for visiting cultural and religious sites in the local a rea

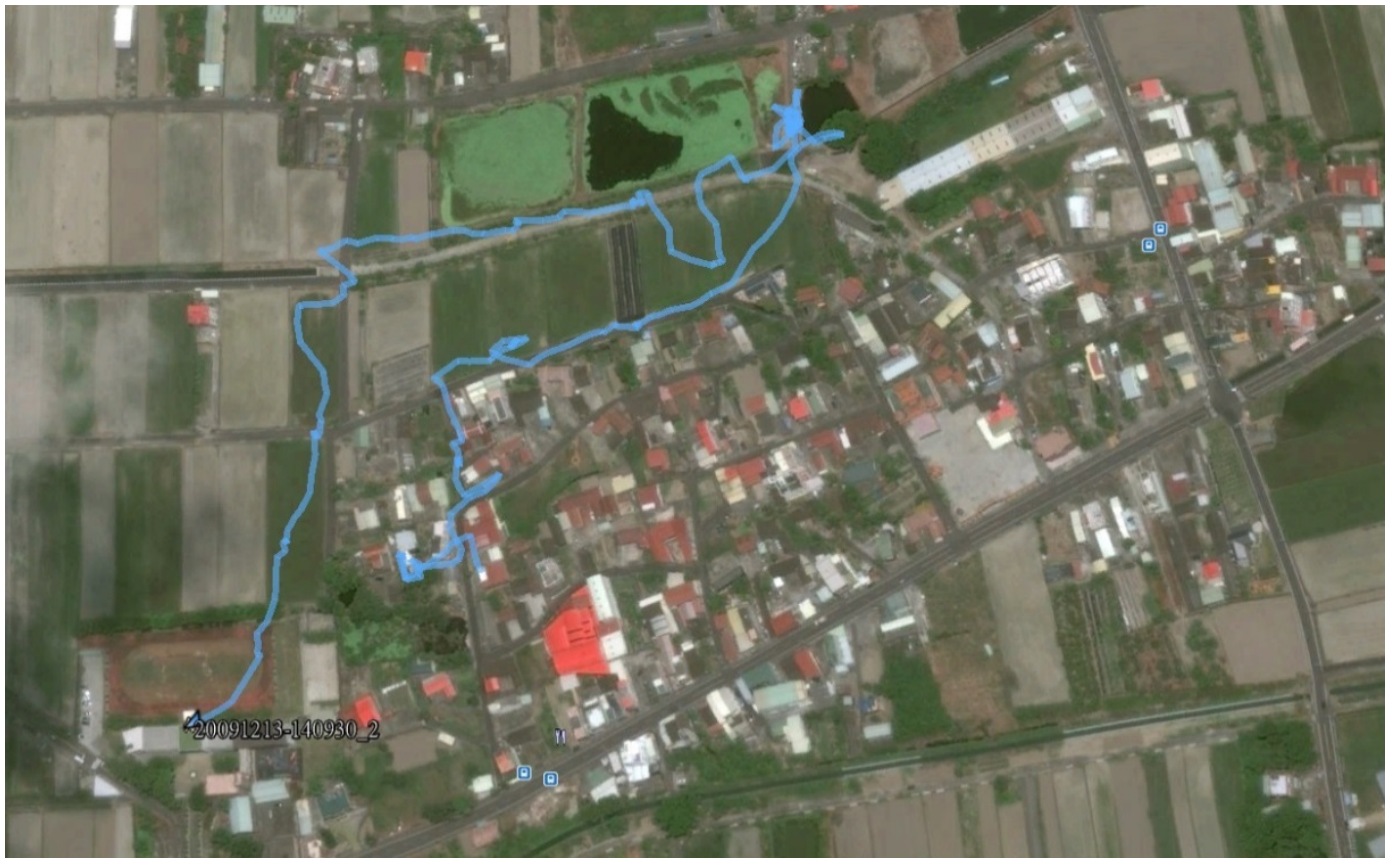

Figure 2: Itinera ry for visiting a gric ultural and a quaculture sites in the loc al a rea 


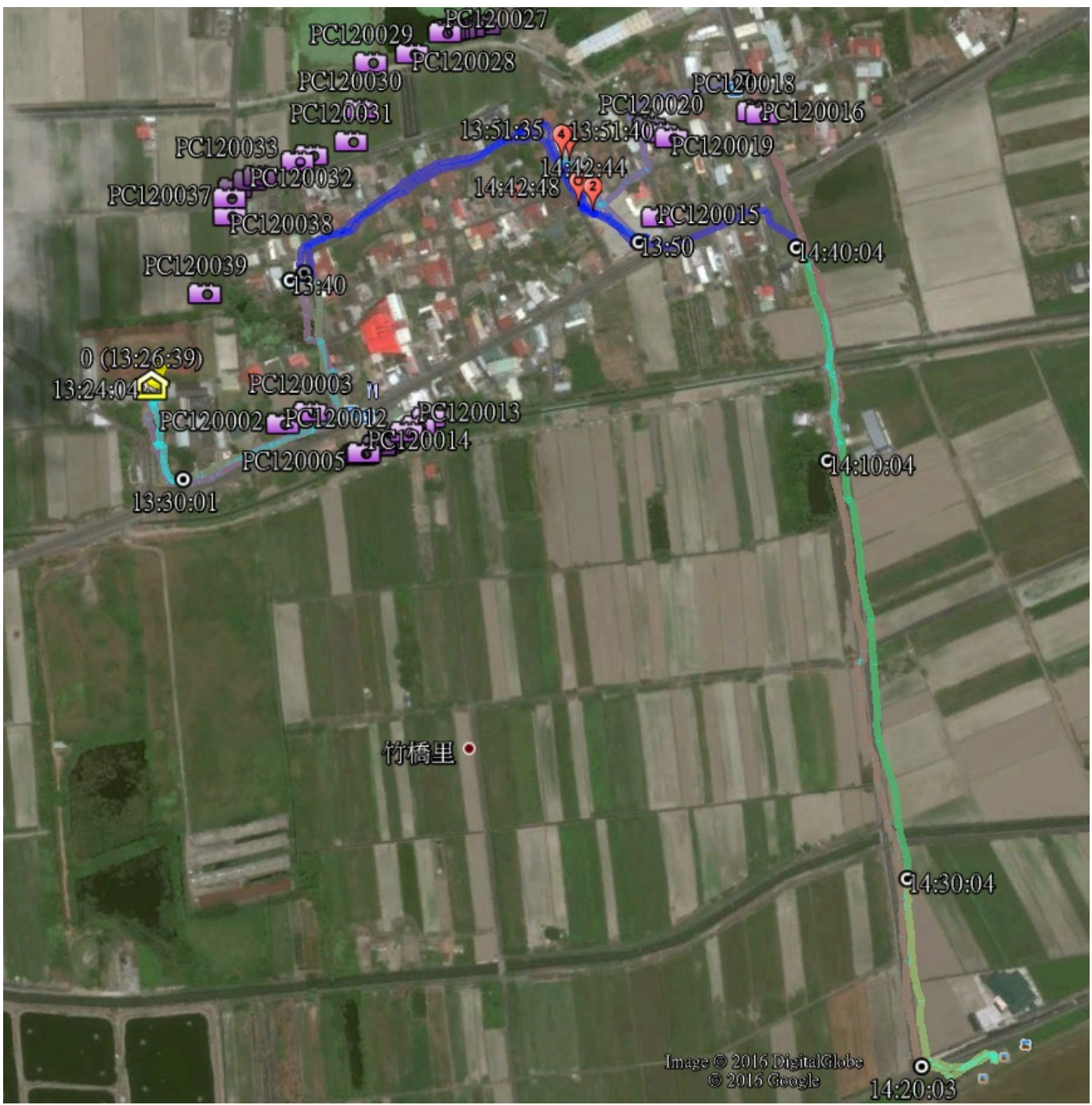

Figure 3: Itinera ry for visiting the local a rea's large river

\section{Findings}

\section{Students' geography capabilities improved}

Overall, the scores of the post-test for all categories were better than the pre-test scores (see Tables 4 and 5). Since the average scores for region boundary, colour and map keys did not increase much, only items relating to view, accuracy, roads and buildings were statistically tested. In other words, the camp activities enhanced students' map skills. As revealed in Table 5, for accuracy and roads the t-test showed that the post-test sketch map score was significantly higher than the score for the pre-test sketch map. With fieldtrip experience and 
hands-on experience using Google, students had clearer and more detailed pictures regarding the route to interesting spots. Thus, students' sketch maps improved in accuracy and number of roads shown. Regarding the map view, after the class more students knew how to use an aerial view to sketch maps.

Table 4: Sketch-map scores

\begin{tabular}{|c|c|c|c|c|c|c|}
\hline \multirow{2}{*}{ Item } & \multirow{2}{*}{$\mathbf{N}$} & \multicolumn{3}{|c|}{ Score } & \multirow{2}{*}{ Avg } & \multirow{2}{*}{ SD } \\
\hline & & Low(1) & Middle(2) & High(3) & & \\
\hline \multicolumn{7}{|l|}{ View } \\
\hline Pre-test & 10 & 5 & 2 & 3 & 1.80 & .919 \\
\hline Post-test & 10 & 1 & 5 & 4 & 2.30 & .675 \\
\hline \multicolumn{7}{|l|}{ Accuracy } \\
\hline Pre-test & 10 & 7 & 3 & 0 & 1.30 & .483 \\
\hline Post-test & 10 & 3 & 5 & 2 & 1.90 & .738 \\
\hline \multicolumn{7}{|l|}{ Roads } \\
\hline Pre-test & 10 & 5 & 4 & 1 & 1.60 & 699 \\
\hline Post-test & 10 & 0 & 6 & 4 & 2.40 & .516 \\
\hline \multicolumn{7}{|l|}{ Buildings } \\
\hline Pre-test & 10 & 2 & 5 & 3 & 2.10 & .738 \\
\hline Post-test & 10 & 0 & 4 & 6 & 2.60 & .516 \\
\hline \multicolumn{7}{|c|}{ Region boundary } \\
\hline Pre-test & 10 & 10 & 0 & 0 & 1.00 & .000 \\
\hline Post-test & 10 & 8 & 0 & 2 & 1.40 & .840 \\
\hline \multicolumn{7}{|l|}{ Colour } \\
\hline Pre-test & 10 & 10 & 0 & 0 & 1.00 & .000 \\
\hline Post-test & 10 & 9 & 1 & 0 & 1.10 & .316 \\
\hline \multicolumn{7}{|l|}{ Map keys } \\
\hline Pre-test & 10 & 10 & 0 & 0 & 1.00 & .000 \\
\hline Post-test & 10 & 8 & 0 & 2 & 1.40 & .840 \\
\hline
\end{tabular}

Table 5: T-test on sketch-map scores

\begin{tabular}{llll}
\hline Item & df & t & $p$ \\
\hline View & 9 & -2.236 & .052 \\
Accuracy & 9 & -2.714 & $.024^{*}$ \\
Roads & 9 & -4.000 & $.003^{*}$ \\
Buildings & 9 & -2.236 & .052 \\
\hline
\end{tabular}

${ }^{*} \mathrm{p}<.05$ 
The paired analysis of students' sketch maps also confirmed students' improved geography capabilities. First, the area presented in the sketch map became larger. Compared with the small areas around their houses in the pre-test map, students could sketch both larger and more detailed maps covering most of their hometown area (see Figures 4 and 5), drawing and labelling more roads, buildings and directions in the post-test map (see Figure 5). The post-test maps were sketched on Day 2, showing that students were able to remember detailed information from the previous day's fieldtrip. Finally, more students adopted an aerial view to sketch the post-test map (see Figure 6).

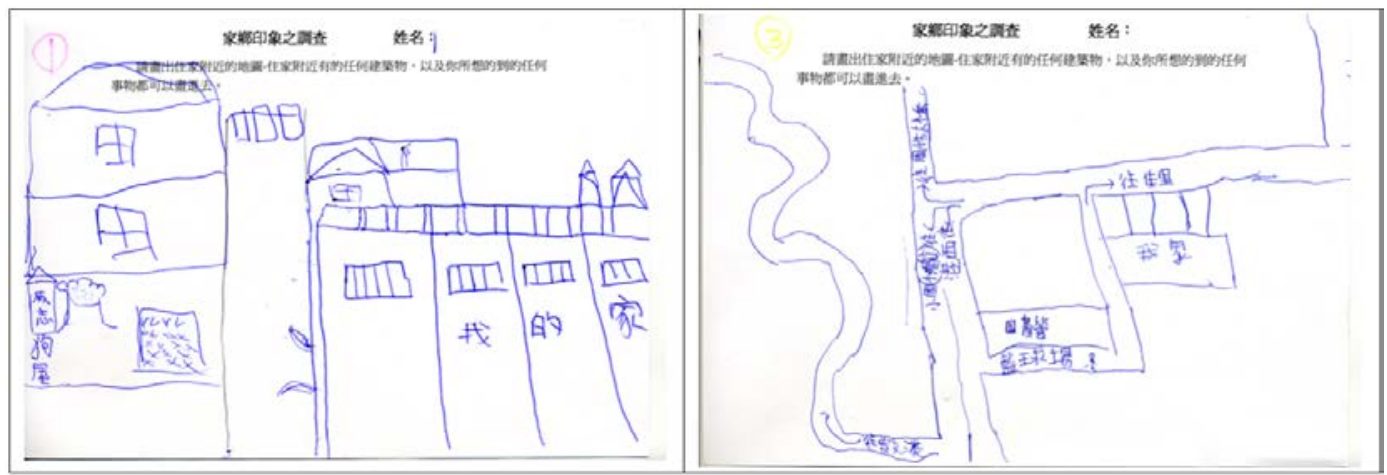

Figure 4: The post-test map (right) presented a wider area than the pre-test map (left)

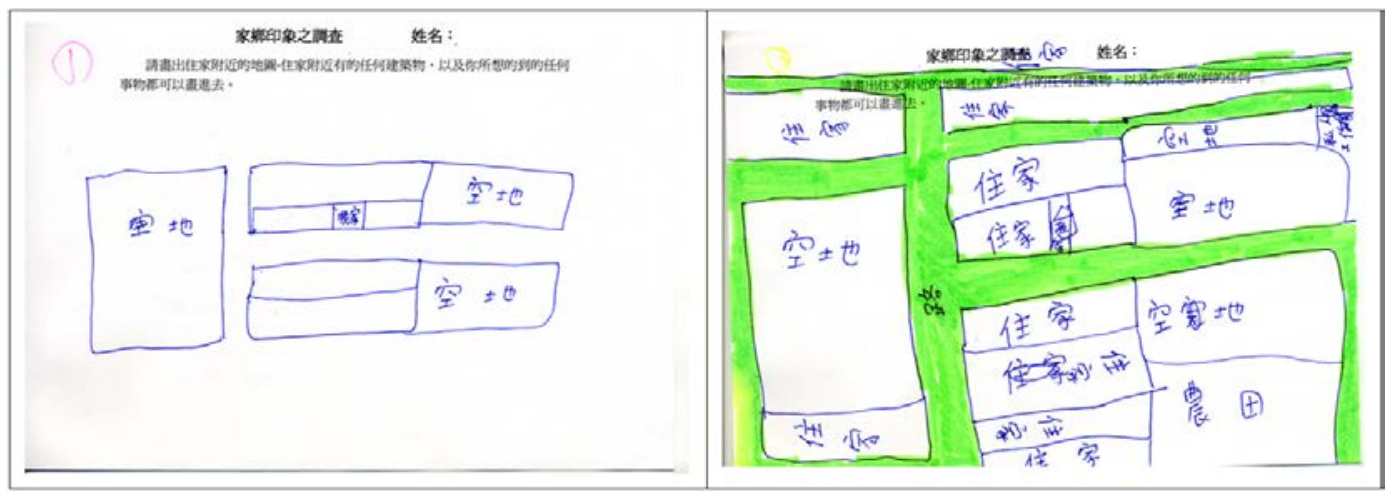

Figure 5: The post-test map (right) presented more content than the pre-test map (left) 


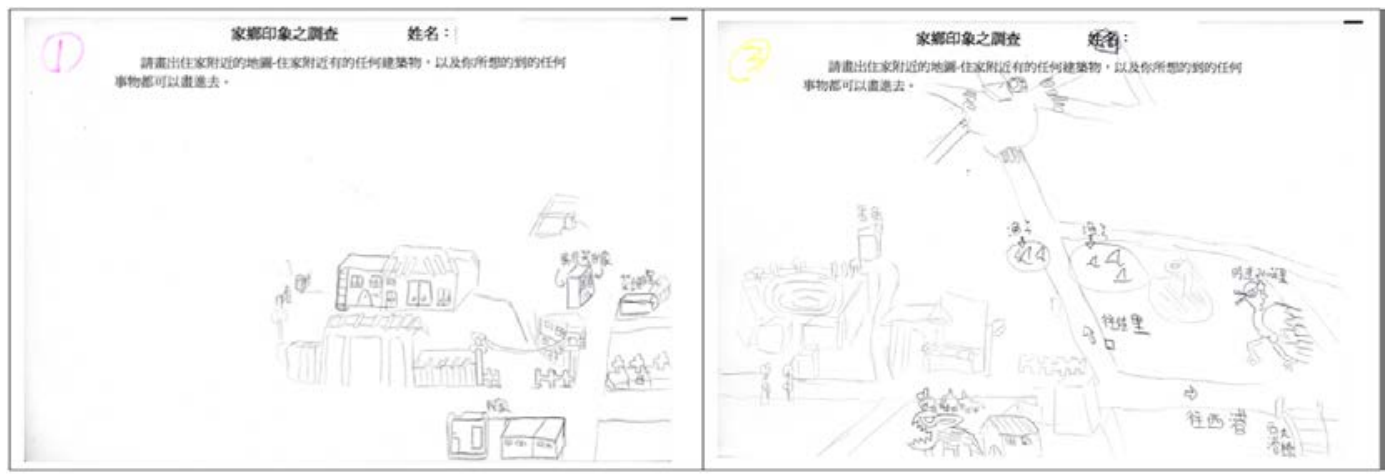

Figure 6: The post-test map (right) is more suggestive of an aerial view than the pre-test map (left)

\section{Students' difficulties using GIS software}

Students learned to use Google Earth and Google Map software easily and energetically. They also actively helped each other and shared the newly-found functions. However, the questionnaires indicated that using GIS was rated the least favorable lesson because students found the software complicated to use and encountered difficulties producing thematic maps. The research assistants had to intervene and gave direct instructions in order to output the thematic maps. Not as user-friendly as Google Maps, professional GIS software needs more knowledge of geography, cartography and professional terms (which confused students, especially when creating map layers). Google Maps and Google Earth are thus better choices than GIS software for students at elementary school.

\section{Students developed a positive attitude towards geography and spatial technologies.}

Their frustrating experience of using GIS to produce thematic maps of their hometown aside, students enjoyed spatial technology like GPS and using cameras during field investigations. The questionnaires and interviews indicated that they had a positive attitude towards the camp's activities. First, they considered spatial technologies useful tools for planning walking itineraries. Google Maps and Google Earth were fun to use for exploring the details of their hometown. In addition, students stated that they had gained new information about their local community and had become more familiar with features of their hometown.

\section{Students' contextual awareness need to be improved}

According to the questionnaires, only one student had ever been on any fieldtrip in the local area - a bird-watching tour. Students had limited knowledge of the area and community in which they lived; their knowledge of homeland subject matter is limited to what they gain from textbooks for examination purposes. Fieldtrips in the neighbourhood, not related directly to textbook content, are frequently neglected by teachers because of scheduling and 
safety concerns. Nevertheless, lack of knowledge about and attention to the living community will lead to indifference towards the local environment. The interaction during fieldtrips revealed that students were unaware of the status or changes of their surroundings. For example, during the fieldtrips students could not identify major cultivated crops such as sesame, even though the air was full of the aroma of sun-drying sesame seeds on the ground. Furthermore, students did not know the history and associated traditional belief of gandangs, which are nevertheless scattered all over road intersections to help protect the community. Awareness of the surrounding environment and community will not be developed without experiencing and interacting directly with nature and people.

\section{Conclusion}

Although homeland education is part of the social studies curriculum, the standard textbook presents an unfamiliar city's history and geography, rather than students' daily surroundings. Leading students to use technology for exploring and recording hometown affairs during local fieldtrips will help them to learn in ways that are meaningful to them. The qualitative and quantitative analysis confirmed the effectiveness of spatial technology in promoting students' geography knowledge and map skills. Nevertheless, the study revealed students' lack of contextual awareness and of knowledge of local customs.

The findings reveal that Google Earth or Google Maps, rather than GIS software, are better tools for elementary students to learn map skills. Geotagging photographs taken during the fieldtrips provides opportunities for students to obtain geographical knowledge about their local community. In addition to map skills, students improved their knowledge of geographic content through the use of spatial technologies. As the results imply, exploring the local community during fieldtrips using user-friendly spatial technology will engage elementary students in authentic learning. In recent years, online GIS software such as Story Map have been increasingly adopted to support project-based learning in the context of social studies. The combination of spatial technology and fieldtrips presented here achieved similar effects: students are able to explore, collect and integrate information with spatial technology, and thus develop their awareness of changes in their surroundings, which will lead to commitment and a positive attitude towards the local environment.

In this study, the participation of university students helped to make the learning activities run more smoothly. Obtaining resources is crucial for innovative teaching. Recruiting volunteers and obtaining grants to hire part-time teachers for intensive, project-based learning programmes during weekends or summer vacations will create a positive learning experience for students. In addition, many emerging spatial technology application packages, such as iNaturalist or Survey123, are becoming more user-friendly, making the conversion of data into visual presentations easier. By designing learning activities utilizing these technologies in an authentic environment, educators will be able to promote students' development in geography knowledge, skills and attitude. 


\section{References}

Chiodo, J. J. (1997). Improving the cognitive development of students' mental maps of the world. Jourrnal of Geography, 96(3), 153-163.

Fuller, I. C. (2006). What is the value of fieldwork? Answers from New Zealand using two contrasting undergraduate physical geography field trip. New Zealand Geographer, 62(3), 215-220.

Gaillard, J. C., \& McSherry, A. (2014). Revisiting Geography Field Trips: A Treasure Hunt Experience. Journal of Geography, 113(4), 171-178.

Huang, K. H. (2011a). A GIS-Interface Web Site: Exploratory Learning for Geography Curriculum. Journal of Geography, 110(4), 158-165. doi:10.1080/00221341.2011.542474

Huang, K. H. (2011b). Learning in Authentic Contexts : Projects Integrating Spatial Technologies and Fieldwork. Journal of geography in higher education, 35(4), 565-578.

Jadallah, M., Hund, A. M., Thayn, J., Studebaker, J. G., Roman, Z. J., \& Kirby, E. (2017). Integrating Geospatial Technologies in Fifth-Grade Curriculum: Impact on Spatial Ability and Map-Analysis Skills. Journal of Geography, 116(4), 139-151. doi:10.1080/00221341.2017.1285339

Kawabata, M., Thapa, R. B., Oguchi, T., \& Tsou, M. H. (2010). Multidisciplinary Cooperation in GIS Education: A Case Study of US Colleges and Universities. Journal of Geography in Higher Education, 34(4), 493-509. doi:10.1080/03098265.2010.486896

Kerski, J. J., Demirci, A., \& Milson, A. J. (2013). The Global Landscape of GIS in Secondary Education. Journal of Geography, 112(6), 232-247. doi:10.1080/00221341.2013.801506

Linn, S. E. (1997). The Effectiveness of Interactive Maps in the Classroom: A Selected Example in Studying Africa. Journal of Geography, 96(3), 164-170.

Nielsen, C. P., Oberle, A., \& Sugumaran, R. (2011). Implementing a High School Level Geospatial Technologies and Spatial Thinking Course. Journal of Geography, 110(2), 60-69. doi:10.1080/00221341.2011.534171

Nieścioruk, K. (2016). The Use of Mental and Sketch Maps as a Tool to Evaluate Cartography Teaching Effectiveness. Journal of Geography, 53(2), 186-196.

Perkins, N., Hazelton, E., Erickson, J., \& Allan, W. (2010). Place-Based Education and Geographic Information Systems: Enhancing the Spatial Awareness of Middle School Students in Maine. Journal of Geography, 109(5), 213-218. doi:10.1080/00221341.2010.501457

Remmen, K. B., \& Froyland, M. (2013). Implementation of guidelines for effective fieldwork designs: exploring learning activities, learning processes, and student engagement in the classroom and the field. International Research in Geographical and Environmental Education, 23(2), 103-125.

Rickles, P., \& Ellul, C. (2017). Innovations in and the changing landscape of geography education with Geographic Information Systems. Journal of Geography in Higher Education, 41(3), 305-309. doi:10.1080/03098265.2017.1331210

Shin, E. K. (2006). Using Geographic Information System (GIS) to improve fourth graders' geographic content knowledge and map skills. Journal of Geography, 105(3), 109-120.

Welsh, K. E., France, D., Whalley, W. B., \& Park, J. R. (2012). Geotagging Photographs in Student Fieldwork. Journal of Geography in Higher Education, 36(3), 469-480. 